\title{
Frequencies of dynamic obstructions of the upper respiratory tract in 135 Thoroughbreds during on-board exercise endoscopy
}

\author{
Svenja Oellers ${ }^{1,2}$, Ann Kristin Barton ${ }^{3}$ and Bernhard Ohnesorge ${ }^{l}$ \\ 1 Klinik für Pferde, Stiftung Tierärztliche Hochschule Hannover, Hannover, Germany \\ 2 Pferdeklinik Burg Müggenhausen, Müggenhausen, Germany \\ ${ }^{3}$ Ann Kristin Barton, Klinik für Pferde, Freie Universität Berlin, Berlin, Germany
}

\begin{abstract}
Summary: The frequencies of dynamic obstructions in thoroughbreds were investigated by performing on-board exercise endoscopy in 135 horses. 17 of these horses showed abnormal respiratory noise only and 35 solely poor performance. In 39 cases, both was reported. In addition, 44 horses underwent endoscopy without any clinical signs. In all of 56 horses that exhibited an audible abnormal respiratory noise, an obstruction of the upper respiratory tract was present. Overall, dynamic upper airway obstructions were detected in $72.6 \%$ (98/135). The most commonly diagnosed obstruction was axial deviation of the aryepiglottic fold (ADAF) in 55.1\% of horses (54/98). $24.4 \%$ (24/98) showed palatal instability (PI), 30.6\% (30/98) dorsal displacement of the soft palate (DDSP) and $11.2 \%$ (11/98) arytenoid cartilage collapse (ACC). Furthermore, 53.1\% (52/98) of horses had abnormalities in the area of the vocal folds. Of these horses, 13 had unilateral or bilateral vocal cord collapse (VCC) and 8 displayed vibration of the vocal cords. 31 horses showed axial deviation in the area of the caudal vocal fold (ADPV) as a sole abnormality. By the new description of these ADPV, the origin of the abnormal respiratory noise in a further proportion of horses could be explained. Including ADPV, an obstruction of the upper airways was observed in all horses (100\%) with specified abnormal respiratory noise. If only horses with long or continuous ( $>8 \mathrm{sec}$ ) DDSP were taken into account, abnormal respiratory noise was audible in $93.3 \%$ and poor performance was present in $73.3 \%$. It can thus be assumed that horses with DDSP requiring treatment are clinically apparent either with abnormal respiratory noise or poor performance. Furthermore, it was demonstrated, that in $52.3 \%$ of horses without poor performance or abnormal respiratory noise an dynamic upper airway obstruction was identified.
\end{abstract}

Keywords: Thoroughbreds, dynamic airway obstruction, on-board endoscopy, vocal fold disease, axial deviation of the caudal Plica vocalis

Citation: Oellers S., Barton A. K., Ohnesorge B. (2018) Frequencies of dynamic obstructions of the upper respiratory tract in 135 Thoroughbreds during on-board exercise endoscopy. Pferdeheilkunde 34, 223-231; DOI 10.21836/PEM20180302

Correspondence: Svenja Oellers, angestellt an der Pferdeklinik Burg Müggenhausen, Heimerzheimerstr. 1853919 Weilerswist-Müggenhausen, Germany; svenja.oellers@web.de

\section{Introduction}

Dynamic obstructions of the upper respiratory tract are among the most common causes of poor performance in racehorses. In addition, an abnormal respiratory noise can be detected in a proportion of these horses (Morris and Seeherman 1991, Stick et al. 1992, Kannegieter and Dore 1995, Martin et al. 2000, Dart et al. 2001, Lane et al. 2006a,b, Franklin 2008).

Exercise endoscopy is the diagnostic tool of choice for examination of those horses (Morris and Seeherman 1991, Kannegieter and Dore 1995, Martin et al. 2000, Dart et al. 2001, Lane et al. 2006 a,b, Franklin 2008, Hammer et al. 1998, Parente et al. 2002). The procedure is performed subsequent to an endoscopy at rest, only thus enabling the detection of all potentially present dynamic airway obstructions. By performing only endoscopy at rest, a dynamic airway obstruction cannot be excluded (Hackett et al. 1994, Kannegieter and Dore 1995, Hammer et al. 1998, Dart et al. 2001, Franklin 2008, Lane et al. 2006a,b).

In the past, exercise endoscopy has been performed on a high speed treadmill (Morris and Seeherman 1991, Kannegieter and Dore 1995, Dart et al. 2001, Lane et al. 2006 a,b). However, a simulation of the training and racing conditions and therefore also reaching the performance limit of the horse is easier with an on-board endoscope. Thereby, exercise endoscopy can be performed while the horses do their full-speed workout on their home racecourse. The horse can be ridden by its jockey and worked in its training group together with other horses. Thus, the horses do not have to be familiarized with a treadmill (Franklin et al. 2008, Pollock and Reardon 2009, Demaizieres et al. 2009, Sloet van OldruitenborghOosterbaan and Clayton 1999, Tamzali et al. 2008, Courouce et al. 1999, Franklin and Allen 2017, Allen et al. 2016).

The aim of the present study was to investigate the frequencies of dynamic obstructions in a large number of thoroughbred racehorses and to correlate it with the occurrence of abnormal respiratory noise or poor performance. So the study aimed to include horses displaying clinical symptoms as well as healthy horses. By this, the effect of different grades of airway obstructions should better be assessable.

\section{Material and methods}

Horses

For this study, 135 thoroughbred horses in race training were examined at the respective racecourse of their training yard. The horses of this study belonged to different trainers. All end- 
oscopies were performed within 24 months. 91 horses were presented because of abnormal respiratory noise or poor performance diagnosed by the trainer responsible. Furthermore, 44 clinical healthy horses were randomly chosen for this study from their trainers. Abnormal respiratory noise was specified in the preliminary report and the presence was checked by the investigator at the beginning and end of the gallop work. The allocation of the criterion "poor performance" was based on information provided by the trainer in consultation with the jockeys.

All examined horses were able to participate in the daily training routine and to complete a fast gallop. No orthopedic problems, cardiovascular diseases, diseases of the lower respiratory tract or other diseases were known in these horses. Horses which had been subjected to surgery of the upper airways according to clinical history were excluded from the study. Whether or not the examined horses had already performed in races was not used as a selection criterion for this study.

The average age of the examined horses was 3.5 years $(2$ to 9 years). There were 44 stallions, 48 mares and 43 geldings.

\section{Endoscopy procedure}

Exercise endoscopy was performed during the normal course of morning training at the racing yard. To place and secure the endoscope in position, the horses were restrained manually with a rope twitch. The endoscope $(9.8 \mathrm{~mm}$ endoscope tube, DRS Equipment by Optomed, les Ulis, France, in saddlebags) was inserted into the ventral nasal passage of the left nostril and advanced to a position where the entire larynx of the horse could be easily visualized. Recording commenced immediately after placement of the endoscope. Thus, an endoscopy at rest was recorded initially. Thereby, the horses were standing

\begin{tabular}{lcl}
\hline Table 1 & Nomenclature | Nomenklatur \\
\hline RLN & Recurrent laryngeal neuropathy \\
ACC & Arytenoid cartilage collapse \\
VFD & Vocal fold disease \\
\hline & ADPV & Axial deviation of the caudal plica vocalis \\
& VCC & Vocal cord collapse \\
& VVC & Vibration of vocal cords \\
\hline ADAF & & Axial deviation of the aryepiglottic fold \\
PC & & Dynamic pharyngeal collapse \\
PI & Palate instability \\
DDSP & Dorsal displacement of the soft palate
\end{tabular}

still in the box until at least one swallowing could be triggered. Subsequently, the warm-up phase of the horse at walk and trot and finally the horse's fast work on the track at a gallop was recorded. The length of the gallop was adapted to the age and training level of the horse and was usually between 1500 and 2000 meters. Length and speed of the gallop was selected so that a high level of performance was achieved.

\section{Evaluation}

Endoscopic evaluations for this study were performed after completion of all 135 endoscopies and blinded to case history and findings during examination. Recordings were assessed in real time, slow motion and frame-by-frame view. The beginning of endoscopy was evaluated as endoscopy at rest. Results of laryngeal endoscopy at rest were classified according to the Havemeyer workshop grading system (Dixon et al. 2003). Under exercise, dynamic arytenoid cartilage collapse (ACC) was evaluated according to Rakestraw et. al. 1991, modified according to Go, 2013. At that, grades B of submaximal abduction and $C$ of dynamic collapse were further divided into three subgrades respectively. Axial deviation of the aryepiglottic fold (ADAF) was defined according to King et al. 2001 and dynamic pharyngeal collapse (PC) according to Boyle et al. 2006. Occurrence of a dorsal displacement of the soft palate (DDSP) was classified into rarely short $(<3 \times / 10 \mathrm{sec})$, often short $(>3 \times / 10 \mathrm{sec})$ and long to continuous (>8sec) DDSP.

The analysis and calculation of statistical values were performed using SPSS version 18. The significance threshold was set at $p<0.05$.

\section{Results}

For this study, exercise endoscopy was performed on 135 thoroughbred horses. The proportions of horses with abnormal respiratory noise and/or a history of poor performance as well as the clinically healthy horses are presented in table 2.

\section{Frequencies of dynamic obstructions}

Overall, dynamic upper airway obstruction was detected in 98 horses. Among those, the most commonly diagnosed dysfunction was axial deviation of the aryepiglottic fold (ADAF) in $55.1 \%$ of horses (54/98). $24.4 \%$ of horses (24/98) showed palatal instability (PI). During exercise endoscopy at gallop, dorsal displacement of the soft palate (DDSP) was observed

Table 2 Classification of probands with regard to the presence of abnormal respiratory noise and poor performance | Einteilung der Probanden in Bezug auf das Vorhandensein eines abnormalen Atemgeräuschs und einer Leistungsschwäche

\begin{tabular}{|c|c|c|c|c|}
\hline & \multicolumn{2}{|c|}{ Number } & \multicolumn{2}{|c|}{ Of these with Obstructions } \\
\hline & $\%$ & (n) & $\%$ & (n) \\
\hline Without abnormal respiratory noise / poor performance & 32.6 & $(44)$ & 52.3 & $(23)$ \\
\hline Only abnormal respiratory noise & 12.6 & $(17)$ & 100 & (17) \\
\hline Only poor performance & 25.9 & (35) & 54.3 & (19) \\
\hline Abnormal respiratory noise and poor performance & 28.9 & (39) & 100 & (39) \\
\hline Total & 100.0 & $(135)$ & 72.6 & (98) \\
\hline
\end{tabular}


in 30.6\% (30/98) of horses, whereof 15 showed a long or continuous displacement. DDSP often occurred in combination with other obstructions, particularly with ADAF (OR 4.18, $\mathrm{P}<0.005)$ and palatal instability (OR 18.3, $\mathrm{P}<0.0001)$. A dynamic pharyngeal collapse (PC) was observed in $15.3 \%$ of horses (15/98).

Obstructions were diagnosed also in the area of rima glottidis. This includes, arytenoid cartilage collapse (ACC), as well as findings in the area of the vocal folds, which can be summarised as vocal fold diseases (VFD). ACC was found in $11.2 \%(11 / 98)$ of horses. 6 of those horses showed a com-

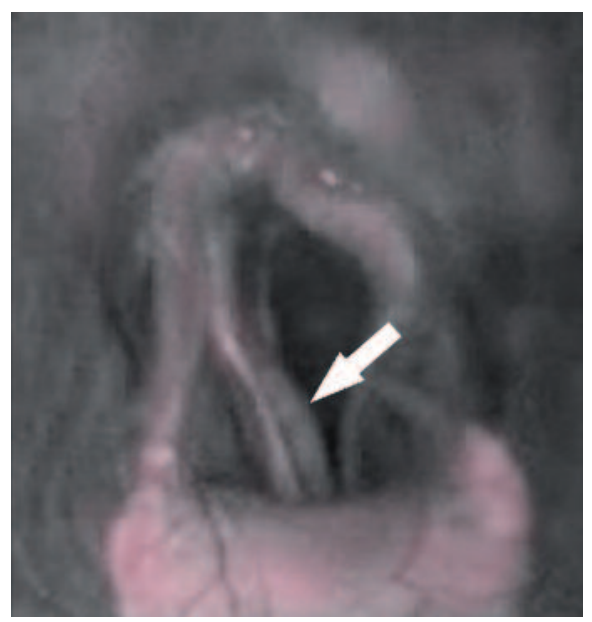

Fig. 1 Axial deviation of the right caudal plica vocalis (ADPV, arrow), in combination with a arytenoid collaps (ACC) on the left side. Axiale Deviation der rechten kaudalen Plica vocalis (ADPV, Pfeil), hier in Kombination mit einem Aryknorpelkollaps (ACC) links

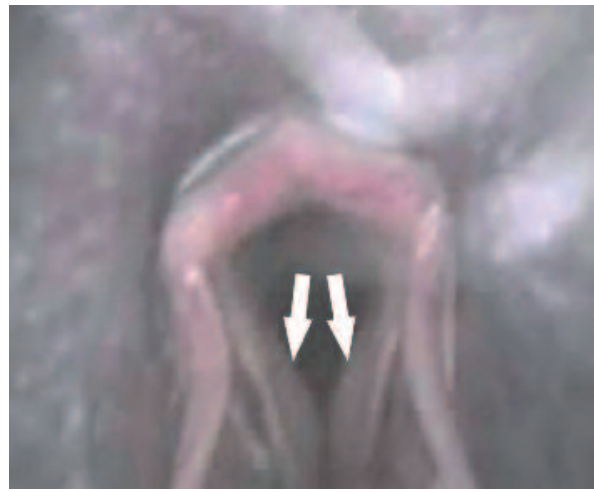

Fig. 2 Axial deviation of both caudal plicae vocales (ADPV, arrows) during inspiration. I Axiale Deviation beider kaudalen Plicae vocales (ADPV, Pfeile) während der Inspiration

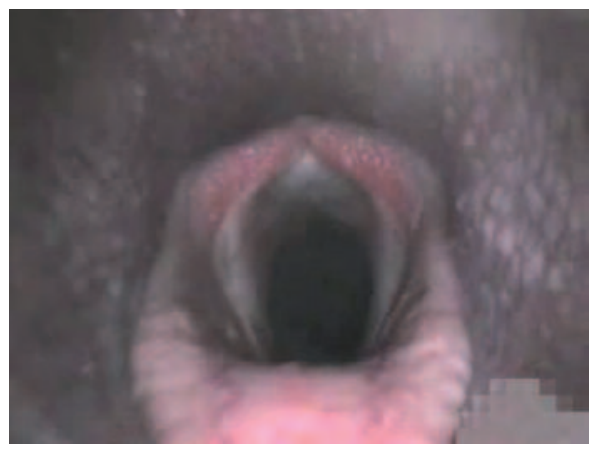

Fig. 3 The same horse as in Fig. 2 at the end of expiration. Das selbe Pferd wie in Abb. 2 am Ende der Expiration plete collapse and one horse had an immobile, but still stable arytenoid cartilage. The other 4 horses were capable of maintaining submaximal abduction. Three horses showed bilateral vocal cord collapse (VCC). In 10 horses, unilateral collapse of the left vocal cord was detected, 9 of these horses also showed left-sided ACC. Vibration of one or both vocal cords (VC) was observed in 8 horses.

In addition, by closer inspection of the area of the rima glottidis, many horses showed a further significant abnormality of the vocal fold which is located caudal of the vocal cord. In these horses, the vocal cord remained fully stretched and showed no signs of deviation, whereas the corresponding caudal area of the vocal fold bulged medially like a sail. This deviation was seen only during inspiration. The extent of this deviation was from a few millimetres up to an obstruction of two-thirds of the ventral glottis area (see Fig. 1, 2 and 3). This finding has not yet been described as a separate obstruction, so it was named axial deviation of the caudal plica vocalis (ADPV). 31 horses showed ADPV without any collapse of the arytenoid or the vocal cord, 27 of these bilateral and 4 unilateral. Furthermore, in 9 out of the 10 cases of left-sided vocal cord collapse, ADPV occurred on the right hand side.

Respiratory noise / performance - respiratory tract obstructions

Abnormal respiratory noise (RN) was found in 56 of the 135 horses examined (41.5\%); 38 showed inspiratory noise, 14 had expiratory noise and 4 showed inspiratory and expiratory noises. In all 56 horses with abnormal respiratory noise, obstruction of the upper respiratory tract was detected. Out of these 56 horses, 39 horses (75\%) also had a history of poor performance.

Among the horses with abnormal respiratory noise, 59\% $(33 / 56)$ showed findings in the area of the vocal folds (VFD). These included the 13 horses (23.2\%) which exhibited unilateral or bilateral vocal cord collapse as well as 15 horses (26.8\%) with ADPV (1 4 bilateral and 1 unilateral). In $17.9 \%$ of horses (10/56), ACC were observed; 9 of these horses showed poor performance as well. ADAF occurred in $42.9 \%$ $(24 / 56)$ of horses with abnormal respiratory noise; $17.9 \%$ $(10 / 56)$ showed palatal instability and in $16.1 \%(9 / 56)$ slight dynamic pharyngeal collapse was visible. DDSP was diagnosed in all 18 horses with expiratory noise $(32.1 \%, 18 / 56)$.

58 out of the 74 horses (78.4\%) with poor performance or poor performance and abnormal respiratory noise showed obstruction in the area of the upper respiratory tract. In $60.4 \%(35 / 58)$ of horses, findings in the area of the vocal folds (VFD) were observed, whereof 17.2\% (10/58) showed unilateral or bilateral vocal cord collapse and $39.7 \%(23 / 58)$ had unilateral or bilateral ADPV. Furthermore, ADAF was diagnosed in $51.7 \%$ (30/58 horses), DDSP in 31\% (18/58 horses) and palatal instability in $27.6 \%$ (16/58 horses). $15.5 \%$ of horses with poor performance showed ACC, i.e. 9 out of 11 horses in which ACC were observed at all. The correlation between the diagnosed obstructions and the occurrence of poor performance and abnormal respiratory noise is shown in Table 3. 
Furthermore, $44(32.6 \%)$ of examined horses were clinically healthy. Nevertheless, 23 (52.3\%) of these horses had a visible obstruction in the upper respiratory tract. Among the clinically healthy horses with obstruction, prevalence of dysfunctions was distributed as follows: $56.5 \%$ (13/23) ADAF and $30.4 \%(7 / 23)$ with findings in the area of the vocal folds (VFD), but no horses with a vocal cord collapse. One horse (4.4\%) showed ACC, but only grade B 1. In addition, $52.2 \%$ of horses showed a palatal dysfunction: $26.1 \%(6 / 23)$ DDSP and $26.1 \%(6 / 23)$ palatal instability.
Resting endoscopic findings vs. exercising endoscopic findings

The relationship between the resting RLN findings and exercising findings in the area of rima glottidis are shown in tables 4 and 5 . In 11 out of 98 horses (11.2\%) with obstructions of the upper respiratory tract left ACC were detected under exercise. 10 out of these 11 horses (91\%) also showed endoscopic findings of left-sided RLN within grade III at rest. In 52 cases $(53.1 \%)$, there were findings in the area of the vocal

Table 3 Relationship between abnormal respiratory noise (RN)/ poor performance (PP) and occurring obstructions | Beziehung zwischen einem abnormalen Atemgeräusch (RN) / einer Leistungsschwäche (PP) und aufgetretenden Obstruktionen

\begin{tabular}{|c|c|c|c|c|c|}
\hline Obstruction & $n$ & RN - & $\mathrm{RN}+$ & PP - & $\mathrm{PP}+$ \\
\hline $\mathrm{ACC}$ & 11 & $1(1)$ & $10(8)$ & $2(2)$ & $9(7)$ \\
\hline VFD & 52 & $19(8)$ & $33(9)$ & $17(7)$ & $35(10)$ \\
\hline - VCC & 13 & $0(0)$ & $13(2)$ & $3(1)$ & $10(1)$ \\
\hline - ADPV & 31 & $16(7)$ & $15(6)$ & $8(5)$ & $23(8)$ \\
\hline ADAF & 54 & $30(10)$ & $24(4)$ & $24(10)$ & $30(4)$ \\
\hline DDSP & 30 & $12(1)$ & $18(2)$ & $12(3)$ & $18(0)$ \\
\hline - DDSP (perm.) & 15 & $1(0)$ & $14(2)$ & $4(2)$ & $11(0)$ \\
\hline PI & 24 & $20(4)$ & $4(0)$ & $8(2)$ & $16(2)$ \\
\hline PC & 15 & $6(1)$ & $9(0)$ & $4(0)$ & $11(1)$ \\
\hline
\end{tabular}

( ) : Horses with this obstruction only, except ACC; here, VCC was not weighted as an separate disease.

Respiratory noise RN + : ACC, VFD, VCC, ADAF, PI, PC: Inspiratory respiratory noise; DDSP : Exspiratory respiratory noise

Table 4 Relationship between resting RLN left sided and exercising VFD - Beziehung zwischen einem RLN Befund des linken Aryknorpels und einem Befund im Bereich der Stimmfalten in Belastung

\begin{tabular}{|c|c|c|c|c|c|c|c|}
\hline \multirow[b]{2}{*}{ VFD in gallop } & \multicolumn{7}{|c|}{ RLN at rest } \\
\hline & I & $\|-1$ & II-2 & III-1 & III-2 & III-3 & Total \\
\hline Without VFD & 23 & 31 & 27 & 2 & - & - & 83 \\
\hline VCC left side & - & - & - & - & 1 & - & 1 \\
\hline VCC left side and ADPV right side & - & - & 2 & 1 & 4 & 2 & 9 \\
\hline ADPV one or both sides & 7 & 16 & 7 & 1 & - & - & 31 \\
\hline VCC both sides & - & 3 & - & - & - & - & 3 \\
\hline Vibration of one or both vocal cords & 1 & 5 & 1 & - & 1 & - & 8 \\
\hline Total & 31 & 55 & 37 & 4 & 6 & 2 & 135 \\
\hline
\end{tabular}

RLN: Recurrent laryngeal neuropathy, VFD: Vocal fold disease with: VCC: Vocal cord collapse, ADPV: Axial deviation in the area of the caudal plica vocalis

Table 5 Relationship between resting RLN left sided and exercising ACC | Beziehung zwischen Ruhe RLN Befund des linken Aryknorpels und dem Auftreten eines Aryknorpelkollapses in Belastung

\begin{tabular}{|c|c|c|c|c|c|c|c|}
\hline \multirow[b]{2}{*}{ ACC in gallop } & \multicolumn{7}{|c|}{ RLN at rest } \\
\hline & I & $11-1$ & II-2 & III-1 & III-2 & III-3 & Total \\
\hline Normal & 31 & 55 & 36 & 2 & - & - & 124 \\
\hline RB1 & - & - & - & 1 & 1 & - & 2 \\
\hline RB3 & - & - & - & 1 & 1 & - & 2 \\
\hline $\mathrm{RCl}$ & - & - & - & - & 1 & - & 1 \\
\hline $\mathrm{RC} 2$ & - & - & - & - & 1 & - & 1 \\
\hline $\mathrm{RC} 3$ & - & - & 1 & - & 2 & 2 & 5 \\
\hline Total & 31 & 55 & 37 & 4 & 6 & 2 & 135 \\
\hline
\end{tabular}

RB 1: Arytenoid cartilage in submaximal abduction, temporal complete abduction possible; RB3: Arytenoid cartilage mostly in submaximal abduction position, position stable, VCC or ADPV; RC1: Arytenoid cartilage does not show any movement, but position remains stable; RC2: Arytenoid cartilage is not abducted and collapses to the median of the rima glottis; RC3: Arytenoid cartilage is not abducted and collapses via the median of the rima glottis (complete collapse), according to Rakestraw 1991, mod. by Go 2013 
folds (VFD) visible during exercise endoscopy. Out of these 52 horses, 42 horses (80.8\%) showed an RLN grade I or II at rest. Among these 42 horses, 2 had a unilateral vocal cord collapse under exercise. Furthermore, all three horses with a bilateral vocal cord collapse under exercise were classified as RLN grade II- 1 at rest (see tab. 4 and 5).

Horses with ADAF, DDSP and palatal instability were predominantly without RLN findings in grade I or II, although one horse with DDSP had a grade III- 1 at rest. Thus, 86 (87.8\%) out of the 98 horses which showed dynamic obstruction under exercise had no RLN findings during endoscopy at rest.

Out of the 30 horses with DDSP at a gallop, 22 (73.3\%) showed no dorsal displacement of the soft palate at rest. In the remaining 8 horses (26.7\%), spontaneous dorsal displacement at rest was observed.

\section{Discussion}

Among the 135 horses examined, 91 (67.4\%) horses had abnormal respiratory noise and/or a history of poor performance; in $82.4 \%$ (75 horses) of those horses, obstruction of the upper respiratory tract was diagnosed. In total, however, obstruction of the upper respiratory tract was diagnosed in 98 (72.6\%) of 135 horses examined.

\section{Clinically healthy horses}

Out of the 98 horses with obstructions of the upper respiratory tract, 23 horses $(23.5 \%)$ showed no clinical findings, i.e. neither an abnormal respiratory noise nor noticeable poor performance. Thus, the obstructions detected in these horses have to be considered as incidental findings. However, in almost all of those horses the grade of the detected dysfunction was so low that it would also have been questioned whether it was the only cause for performance impairment. In one horse, however, dorsal displacement of the soft palate lasting up to a few minutes was diagnosed. At the time of endoscopy, it had no effect on the horse's performance yet, although considerable obstruction of the upper respiratory tract was present. In addition, a mild form of ADAF and palatal instability was observed in this horse. This shows that obstructions can also be present in certain numbers of clinically healthy horses. Therefore, particularly in horses showing poor performance, findings detected should always be scrutinised and compared to the horse's clinical signs to ascertain whether they can really be the sole cause for poor performance. Thus, a targeted treatment can be applied. In 1991, Morris and Seeherman et al. already described more than one cause for poor performance in $84 \%$ of horses and found a dynamic obstruction to be the cause in only $24 \%$ of cases. Martin et al., 2000, also showed that dynamic airway obstruction as the cause of poor performance in only 148 of 348 horses (42.6\%).

Horses with poor performance, but without abnormal respiratory noise

In the group of horses with history of poor performance, but without abnormal respiratory noise, respiratory findings were also mostly of a low grade. $45.7 \%$ of them showed no respiratory findings. $A D A F, A D P V$, or palatal instability was visible in the others. These findings could be the cause of poor performance in those horses. It has to be considered, however, that some of these findings are incidental, such as in the group of horses without abnormal respiratory noise or poor performance, which are possibly not or not solely causative for the horses' poor performance. At least, in a proportion of horses, the cause of poor performance could not be explained by an obstruction of the upper airways.

\section{Frequencies of dynamic obstructions}

The most commonly diagnosed respiratory finding in the horses with an airway obstruction during exercise endoscopy was axial deviation of the aryepiglottic fold (55.1\%), similarly to Tan et. al. 2005 (55\%) and in contrast to other studies (Dart et al. 2001, Kannegieter and Dore 1995, King et al. 1997, Parente et al. 1998, Martin et al. 2000, Lane et al. 2006a). ADAF frequently occurred in combination with DDSP (20 horses), for which a significant correlation was determined (OR 4.18, $P<0.005)$. This is in accordance with other studies (Lane et al. 2006a, Stick et al. 1999, Parente et al. 1994, 1997, Robertson et al. 1998, Franklin and Allen 2017). Combined occurrence of ADAF and findings in the area of the vocal fold was also common. In this study, the number of horses with ADAF showing abnormal respiratory noise (44\%) or poor performance (56\%) is slightly lower than in other studies (King et al. 1997: $83 \%$ abnormal respiratory noise; Martin et al. 2000: 100\% abnormal respiratory noise). This is explained by the fact that among the horses with an obstruction there were also horses without clinical symptoms which were not subjected to examination in other studies.

The number of horses with DDSP in this study was comparable to other studies (Morris and Seeherman 1991, Kannegieter and Dore 1995, Martin et al. 2000, Tan et al. 2005, Desmaizieres et al. 2009, Barakzai and Dixon 201 1). However, this dysfunction was diagnosed as the sole obstruction in only $10 \%$ of horses. It was often accompanied by ADAF, palatal instability or ADPV.

In the present study, as in other studies (50-81\% abnormal respiratory noise), expiratory noise was only audible in about two thirds of horses (60\%) with DDSP (Lumsden et al. 1995, Stick et al. 1999, Martin et al. 2000, Parente et al. 2002, Tan et al. 2005). If, however, only the most severe form of DDSP from this evaluation with long $(>8 \mathrm{sec}$ ) or continuous displacement of the soft palate until the end of exercise is taken into account, abnormal respiratory noise was audible in $93.3 \%$ (all but one horse). Out of these horses with continuous DDSP, $73.3 \%$ (11 horses) also showed poor performance. It can thus be assumed that horses with DDSP requiring treatment are clinically apparent either with abnormal respiratory noise or poor performance.

In $73.3 \%$ of horses with DDSP at gallop, no dorsal displacement of the soft palate was detected at rest. Only $18.6 \%$ of the 43 horses with spontaneous DDSP at rest showed displacement under exercise. Thus, no conclusion can be drawn from spontaneous DDSP during endoscopy at rest for DDSP under exercise. This has already been shown in several other 
studies (Kannegieter and Dore 1995, Parente et al. 2002, Lane et al. 2006b, Franklin 2008, Barakzai and Dixon 2011).

In this study, left-sided ACC were diagnosed in a small number of horses with obstruction of the upper respiratory tract (1 1.2\%), similar to the study by Lane et al. 2006a. Almost all of these horses showed abnormal inspiratory noise $(91 \%)$ as well as poor performance (82\%). In $82 \%$ of horses, these leftsided ACC appeared in combination with left-sided vocal cord collapse and right-sided ADPV. This shows the strong correlation of ACC with additional findings in the area of the vocal folds (VFD), which probably occur here due to the loss of tension of the left arytenoid cartilage and the altered air pressure in the area of the rima glottidis.

Furthermore, findings in the area of the vocal folds (VFD) also appeared as entirely independent dysfunctions without any relation to ACC under exercise and RLN findings at rest. In particular, bilateral vocal cord collapse and unilateral or bilateral axial deviation in the area of the caudal vocal fold (ADPV) respectively became apparent. ADPV was observed in a significant number of horses (31.6\%) with airway obstruction and has so far not been described as an independent obstruction. The exact cause is unknown so far, but neurogenic atrophy could be the underlying cause. This, however, does not provide a satisfactory explanation for the common bilateral occurrence. The correlation between RLN and the various obstructions in the area of the rima glottidis could be subject to further examinations. In previous studies, neurogenic atrophy of the laryngeal muscles has only been assessed related to ACC. Possibly all these forms of the laryngeal stenosis are consequences of an RLN in different manifestations.

Resting endoscopic findings vs. exercise endoscopic findings Despite some exceptions, an abduction deficit of the left arytenoid cartilage can be reasonably predicted by endoscopy at rest (Parente 2018). In this study, $83.3 \%$ of horses with an RLN within grade III at rest also showed ACC under exercise. Only 2.7\% (1 horse) with an RLN grade II-2 at rest showed ACC under exercise.

As with ADAF, DDSP and PI, with the exception of ACC, obstructions of the rima glottidis could not be detected during endoscopy at rest. Thus, a sole endoscopy at rest does not enable a prediction of the findings under exercise for VCC and ADPV respectively. Therefore, an exercise endoscopy is always required in order to reach a definite diagnosis (Kannegieter and Dore 1995, Parente et al. 2002, Lane et al. 2006b, Franklin 2008, Barakzai and Dixon 2011).

\section{Horses with abnormal respiratory noise}

In this study, $100 \%$ of horses with abnormal respiratory noise were also diagnosed with obstruction of the upper respiratory tract. Other studies have shown significantly lower values (44-86\% with obstruction) (Morris and Seeherman 1990, Stick et al. 1992, Kannegieter and Dore 1995, Tan et al. 2005, Witte et al. 2011). This can clearly be explained by the evaluation of all findings in the area of the vocal folds (VFD). Without their evaluation, obstruction of the upper respiratory tract would only be detectable in $87.5 \%$ of horses with abnormal respiratory noise. This ADPV is not necessarily the sole cause for the horse's poor performance. In this study, poor performance was reported for $74.2 \%$ of horses showing this obstruction among others. Nevertheless, this dysfunction leads to a vibration of air during inspiration and can thus cause abnormal respiratory noise.

\section{Conclusions}

This study once more proves the importance of carrying out a thorough diagnostic investigation in horses showing poor performance. The extent to which obstructions of the upper respiratory tract also occur in clinically healthy horses was shown. It must thus be assumed that in a proportion of horses presented for poor performance, the diagnosed obstruction is not necessarily the cause or the sole cause but that further dysfunctions may be present as well. In addition, it was demonstrated that other than for ACC, endoscopy at rest provides no indication regarding the dynamic obstructions in exercising horses. Through the description of axial deviation in the area of the caudal vocal fold (ADPV), the origin of the abnormal respiratory noise in further proportion of horses with abnormal respiratory noise could be explained. This should be taken into account during future assessment of respiratory noises. The exact pathology of this dysfunction, however, remains to be investigated.

\section{Acknowledgements}

The authors would like to thank the Burg Müggenhausen equine clinic for providing the on-board endoscope.

\section{Conflict of interest}

The authors report no conflict of interest.

\section{References}

Allen K. J., van Erck-Westergren E., Franklin S. H. (2016) Exercise testing in the equine athlete. Equine Vet. Educ. 28, 89-98

Barakzai S. Z., Dixon P. M. (2011) Correlation of resting and exercising endoscopic findings for horses with dynamic laryngeal collapse and palatal dysfunction. Equine Vet. J. 43, 18-23

Boyle A. G., Martin B. B., Davidson E. J., Durando M. M., Birks E. K. (2006) Dynamic pharyngeal collapse in racehorses. Equine Vet. J. Suppl. 38, 546-550

Couroucé A., Geffroy O., Barrey E., Auvinet B., Rose R. J. (1999) Comparison of exercise tests in French trotters under training track, racetrack and treadmill conditions. Equine Vet. J. Suppl. 30, 528-532

Dart A. J., Dowling B. A., Hodgson D. R., Rose R. J. (2001) Evaluation of high-speed treadmill videoendoscopy for diagnosis of upper respiratory tract dysfunction in horses. Aust. Vet. J. 79, 109-1 12

Desmaizieres L. M., Serraud N., Plainfosse B., Michel A., Tamzali Y. (2009) Dynamic respiratory endoscopy without treadmill in 68 performance Standardbred, Thoroughbred and saddle horses under natural training conditions. Equine Vet. J. 41, 347-352

Dixon P. M., Robinson N. E., Wade J. F. (2003) Workshop summary. In: Proceedings of a Workshop on equine recurrent laryngeal neuropathy, Dixon P. M., Robinson N. E., Wade J. F., R \& W Publications, Newmarket, 93-97

Franklin S. H. (2008) Dynamic collapse of the upper respiratory tract: A review. Equine Vet. Educ. 20, 212-224 
Franklin S. H., Allen K. J. (2017) Assessment of dynamic upper respiratory tract function in the equine athlete. Equine Vet. Educ. 29, 92-103

Go L., Barton A., Ohnesorge B. (2014) Objective classification of different head and neck positions and their influence on the radiographic pharyngeal diameter in sport horses. BMC Veterinary Research 10, 118

Hackett R. P., Ducharme N. G., Mitchell L. (1994) The role of treadmill endoscopy in diagnosis of dynamic obstruction of the upper airway. Proc. Am. Assoc. Equine Pract. 40, 83

Hammer E. J., Tulleners E. P., Parente E. J., Martin B. B. (1998) Videoendoscopic assessment of dynamic laryngeal function during exercise in horses with grade-III left laryngeal hemiparesis at rest: 26 cases (1992-1995). J. Am. Vet. Med. Assoc. 212, 399-403

Holcombe S. J., Derksen F. J., Stick J. A., Robinson N. E. (1999) Pathophysiology of dorsal displacement of the soft palate in horses. Equine Vet. J. Suppl. 31, 45-48

Kannegieter N. J., Dore M. L. (1995) Endoscopy of the upper respiratory tract during treadmill exercise: a clinical study of 100 horses. Aust. Vet. J. 72, 101-107

King D. S., Tulleners E. P., Martin B. B., Parente E. J., Boston R. C. (2001) Clinical experiences with axial deviation of the aryepiglottic folds in 52 racehorses. Vet. Surg. 30,151-160

Lane J. G., Bladon B., Little D. R. M., Naylor J. R. J., Franklin S. H. (2006) Dynamic obstructions of the equine upper respiratory tract. Part 1: observations during high-speed treadmill endoscopy of 600 Thoroughbred racehorses. Equine Vet. J. 38, 393-399

Lane J. G., Bladon B., Little D. R. M., Naylor J. R. J., Franklin S. H. (2006) Dynamic obstructions of the equine upper respiratory tract. Part 2: comparison of endoscopic findings at rest and during highspeed treadmill exercise of 600 Thoroughbred racehorses. Equine Vet. J. 38, 401-407

Lumsden J. M., Stick J. A., Caron J. J., Nickels F. A., Brown C. M., Godber L. M., Derksen F. J. (1995) Upper airway function in performance horses: videoendoscopy during high-speed treadmill exercise. Comp. Cont. Educ. Pract. Vet. 17, 1134-1143

Martin B. B., Reef V. B., Parente E. J., Sage A. D. (2000) Causes of poor performance of horses during training, racing, or showing: 348 cases (1992-1996). J. Am. Vet. Med. Assoc. 216, 554-558

Morris E. A., Seeherman H. J. (1990) Evaluation of upper respiratory tract function during strenuous exercise in racehorses. J. Am. Vet. Med. Assoc. 196, 431-438

Morris E. A., Seeherman H. J. (1991) Clinical evaluation of poor performance in the racehorse: the results of 275 evaluations. Equine Vet. J. 23, 169-174
Parente E. J. (1997) Treadmill endoscopy. In: Equine Endoscopy, Brown C.M., Traub-Dargatz J.L., Mosby, St Louis, 2nd edn., 112

Parente E. J. (2018) Fifty years of recurring struggles with recurrent laryngeal neuropathy. Equine Vet. J. 50, 155-158

Parente E. J., Martin B. B., Tulleners E. P., Ross M. W. (1994) Upper respiratory dysfunctions in the horse during high-speed treadmill exercise. Proc. Am. Ass. Equine Practnrs 40, 81-82

Parente E. J., Martin B. B., Tulleners E. P., Ross M. W. (2002) Dorsal displacement of the soft palate in 92 horses during high-speed treadmill examination (1993-1998). Vet. Surg. 31, 507-512

Pollock P. J., Reardon R. J. M., Parkin T. D. H., Johnston M. S., Tate J., Love S. (2009) Dynamic respiratory endoscopy in 67 Thoroughbred racehorses training under normal ridden exercise conditions. Equine Vet. J. 41, 354-360

Rakestraw P. C., Hackett R. P., Ducharme N. G., Nielan G. J., Erb H. $N$. (1991) Arytenoid cartilage movement in resting and exercising horses. Vet. Surg. 20, 122-127

Robertson J. T. (1998) Dorsal displacement of the soft palate. In: Current Techniques in Equine Surgery and Lameness, White N. A., Moore J. N., Saunders, Philadelphia, USA., 2nd edn., 131-135

Stick J. A., Derksen F. J., Nickels F. A., Brown C. M., Arden W. A., Fulton I. C., Peloso J. G. (1990) Upper airway videoendoscopy during exercise in poorly performing horses. In: Proceedings of the Annual Convention of the American Association of Equine Practitioners 38, $431-438$

Stick J. A., Peloso J. G., Morehead J. P., Lloyd J., Eberhart S., Padungtod P., Derksen F. J. (2001) Endoscopic assessment of airway function as a predictor of racing performance in Thoroughbred yearlings: 427 cases (1997-2000). J. Am. Vet. Med. Assoc. 219, 962-967

Stick J. A., Tulleners E. P., Robertson J. T., Holcombe S. J. (1999) Larynx. In: Equine Surgery, Auer J. A., Stick J. A., Saunders, Philadelphia, USA., 2nd edn., 349-368

Tamzali Y., Serraud N., Baup B., Desmaizieres L. M. (2008) How to perform endoscopy during exercise without a treadmill. In: American Association of Equine Practitioners, Proceedings of the 54th AAEP Annual Convention 54, 24-28

Tan R. H. H., Dowling B. A., Dart A. J. (2005) High-speed treadmill videoendoscopic examination of the upper respiratory tract in the horse: the results of 291 clinical cases. Vet. J. 170, 243-248

van Sloet Oldruitenborgh-Oosterbaan M. M., Clayton H. M. (1999) Advantages and disadvantages of track vs. treadmill tests. Equine Vet. J. Suppl. 30, 645-647

Witte S. H. P., Witte T. H., Harriss F., Kelly G., Pollock P. J. (2011) Association of owner-reported noise with findings during dynamic respiratory endoscopy in Thoroughbred racehorses. Equine Vet. J. 43, 9-17 